Full Research Paper

\title{
Using ASTER Imagery in Land Use/cover Classification of Eastern Mediterranean Landscapes According to CORINE Land Cover Project
}

\author{
Alaaddin Yüksel ${ }^{1, *}$, Abdullah E. Akay ${ }^{1}$ and Recep Gundogan ${ }^{2}$ \\ 1 Kahramanmaras Sutcu Imam University, Faculty of Forestry, Department of Forest Engineering, \\ 46060, Kahramanmaras, Turkey, E-mail: ayuksel@ksu.edu.tr, akay@ksu.edu.tr \\ 2 Kahramanmaras Sutcu Imam University, Faculty of Agriculture, Department of Soil Science, \\ 46060, Kahramanmaras, Turkey, E-mail: rgundogan@ksu.edu.tr
}

* Author to whom correspondence should be addressed; E-mail: ayuksel@ksu.edu.tr, Tel: +90 344 2237666, Fax: +90 3442217244

Received: 7 February 2008 / Accepted: 19 February 2008 / Published: 22 February 2008

\begin{abstract}
The satellite imagery has been effectively utilized for classifying land cover types and detecting land cover conditions. The Advanced Spaceborne Thermal Emission and Reflection Radiometer (ASTER) sensor imagery has been widely used in classification process of land cover. However, atmospheric corrections have to be made by preprocessing satellite sensor imagery since the electromagnetic radiation signals received by the satellite sensors can be scattered and absorbed by the atmospheric gases and aerosols. In this study, an ASTER sensor imagery, which was converted into top-of-atmosphere reflectance (TOA), was used to classify the land use/cover types, according to COoRdination of INformation on the Environment (CORINE) land cover nomenclature, for an area representing the heterogonous characteristics of eastern Mediterranean regions in Kahramanmaras, Turkey. The results indicated that using the surface reflectance data of ASTER sensor imagery can provide accurate (i.e. overall accuracy and kappa values of $83.2 \%$ and 0.79 , respectively) and low-cost cover mapping as a part of inventory for CORINE Land Cover Project.
\end{abstract}

Keywords: Classification, Land use/cover, ASTER, TOA, CORINE 


\section{Introduction}

Monitoring and assessing land use/cover information is very important in managing natural resources. In recent decades, remotely sensed data have been widely used to provide the land use/cover information such as degradation level of forests and wetlands, rate of urbanization, intensity of agricultural activities, and other human-induced changes [1]. In remote sensing technology, classification as a common image processing technique is implemented to derive data regarding land use/cover types [2]. Especially in Mediterranean regions with complex and heterogeneous landscapes, classification techniques are crucial to generate accurate and inexpensive land use/cover maps [3, 4, 5, 6]. Besides, the classification of land use/cover types provides useful information in mapping vegetation and ecosystem types [7, 8, 9]. Then, these thematic maps can be also used to generate necessary database for empirical and process-based models of soil loss, hydrological cycle, and carbon flux [10, 11, 12, 13, 14].

The satellite imagery has been effectively utilized in classification process, especially, in generating land use/cover maps and detecting land cover conditions [6, 15, 16]. Landsat images have been commonly used in the studies of mapping and monitoring natural resources worldwide. Landsat imagery with a moderate spatial resolution of $30 \mathrm{~m}$ has been effectively used to classify homogeneous landscapes [5]; however, their accuracy may diminish in eastern Mediterranean regions with highly heterogeneous landscapes [17].

The Advanced Spaceborne Thermal Emission and Reflection Radiometer (ASTER) has been recently developed by collaboration of NASA and Japan's Ministry of International Trade and Industry to provide accurate satellite images with high spatial and spectral resolutions [18]. The ASTER sensor operates three different spectral regions including the visible and near infrared (VNIR), the short-wave infrared (SWIR), and the thermal infrared (TIR). According to Rowan and Mars [19], the visible and near-infrared telescope on ASTER with a spatial resolution of $15 \mathrm{~m}$ is very useful to acquire vegetative information. The ASTER images with high spatial and spectral resolutions can provide more accurate and low-cost land cover mapping [20, 21, 22].

The electromagnetic radiation (EMR) signals received by the satellite sensors are subject to some type of distortion due to scattering and absorption effects of atmospheric gases and aerosols [23, 24]. Therefore, atmospheric corrections have to be made by converting radiance values to top-ofatmosphere (TOA) reflectance, especially in multispectral VNIR bands [25]. The surface reflectance data results in better calibration of multi-sensor imagery, less blurring effects of atmospheric scattering, and easier interpretation, when comparing with original digital number (DN) value or calibrated radiance data [26, 27, 28, 29].

In classification process, supervised classification has been widely used in remote sensing applications. In supervised classification, spectral signatures are collected from specified locations (training sites) in the image by digitizing various polygons overlaying different land use types. The spectral signatures are then used to classify all pixels in the scene. The supervised classification is generally followed by knowledge-based expert classification systems depending on reference maps to improve the accuracy of the classification process [30, 31].

Expert systems have been successfully implemented in classifying land use/cover types, especially, for heterogeneous landscapes [32, 33]. Besides, expert systems can be used to reclassify the classified images according to some specific land use/cover classification standards. In this study, land use/cover 
classification standards of COoRdination of INformation on the Environment (CORINE) Land Cover Project were used in the process of expert classification system. The CORINE was established by the European Union (EU) in 1985 to generate the European environmental landscape based on interpretation of satellite images and ancillary data [34]. It provides land use/cover maps for European countries for environmentalists and for policy makers.

The main purpose of this study is to perform the land use/cover classification of a study area in the province of Kahramanmaras located in the Mediterranean region of Turkey. The classification was performed on an ASTER sensor imagery, which was converted into TOA reflectance. The capabilities and opportunities of applying ASTER imagery to provide accurate land use/cover classification of heterogeneous Mediterranean landscapes were investigated as a part of inventory for CORINE Land Cover Project.

\section{Material and Methods}

\subsection{Study Area}

The study area is located in the eastern Mediterranean region of Turkey, about $20 \mathrm{~km}$ southeast from the city of Kahramanmaras (Figure 1). The study area covers approximately 21000 ha of land with the elevation of 500 to $850 \mathrm{~m}$ and slope of 0 to $39 \%$. The area represents the heterogonous characteristics of the eastern Mediterranean regions consisting of the wide variety of agricultural systems (i.e. fallow land, rainfed and irrigated field crops), forest ecosystems, rangelands, shrub lands, bare rocks, wetland, water bodies, and residential areas.

\subsection{Image Processing}

The image processing was performed in four stages including preprocessing, converting ASTER radiance values to reflectance, land use/cover classification, and expert classification. The logic behind the image processing techniques was indicated in Figure 2.

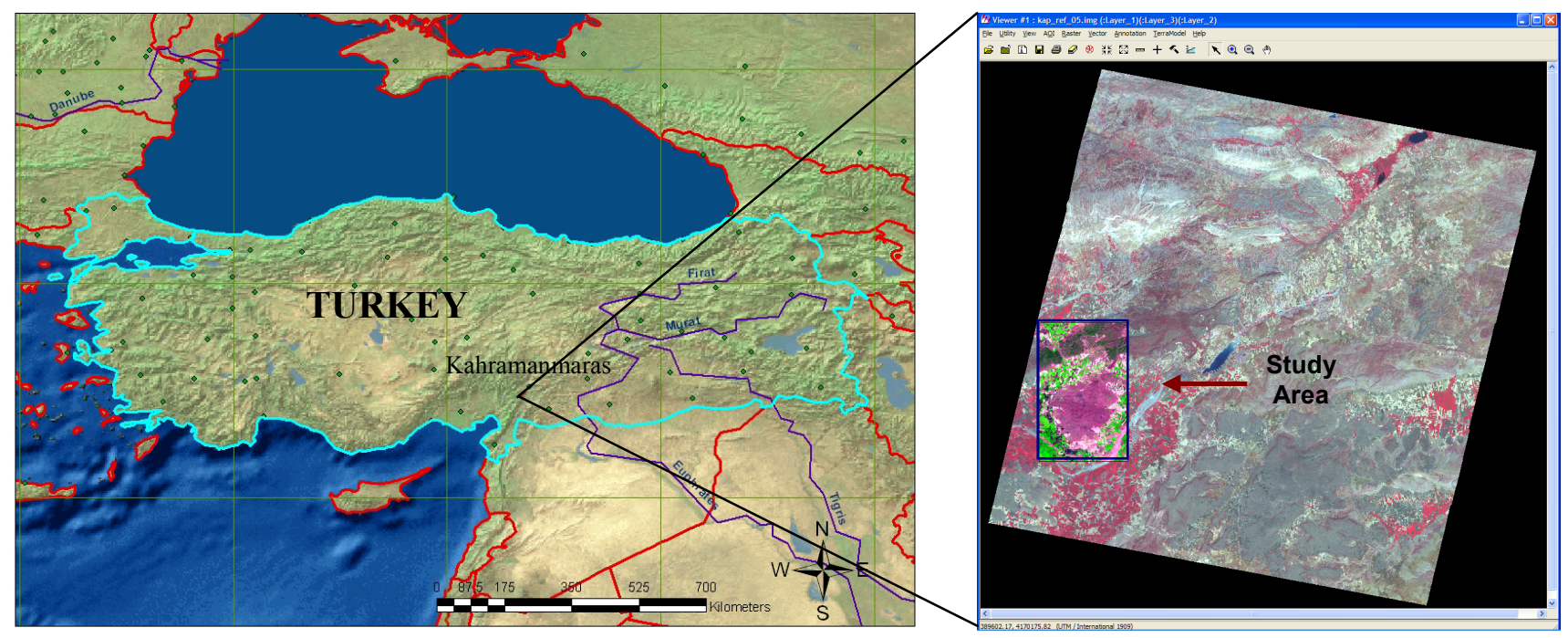

Figure 1. The location of the study area on the topographic map of Turkey and on the ASTER image. 


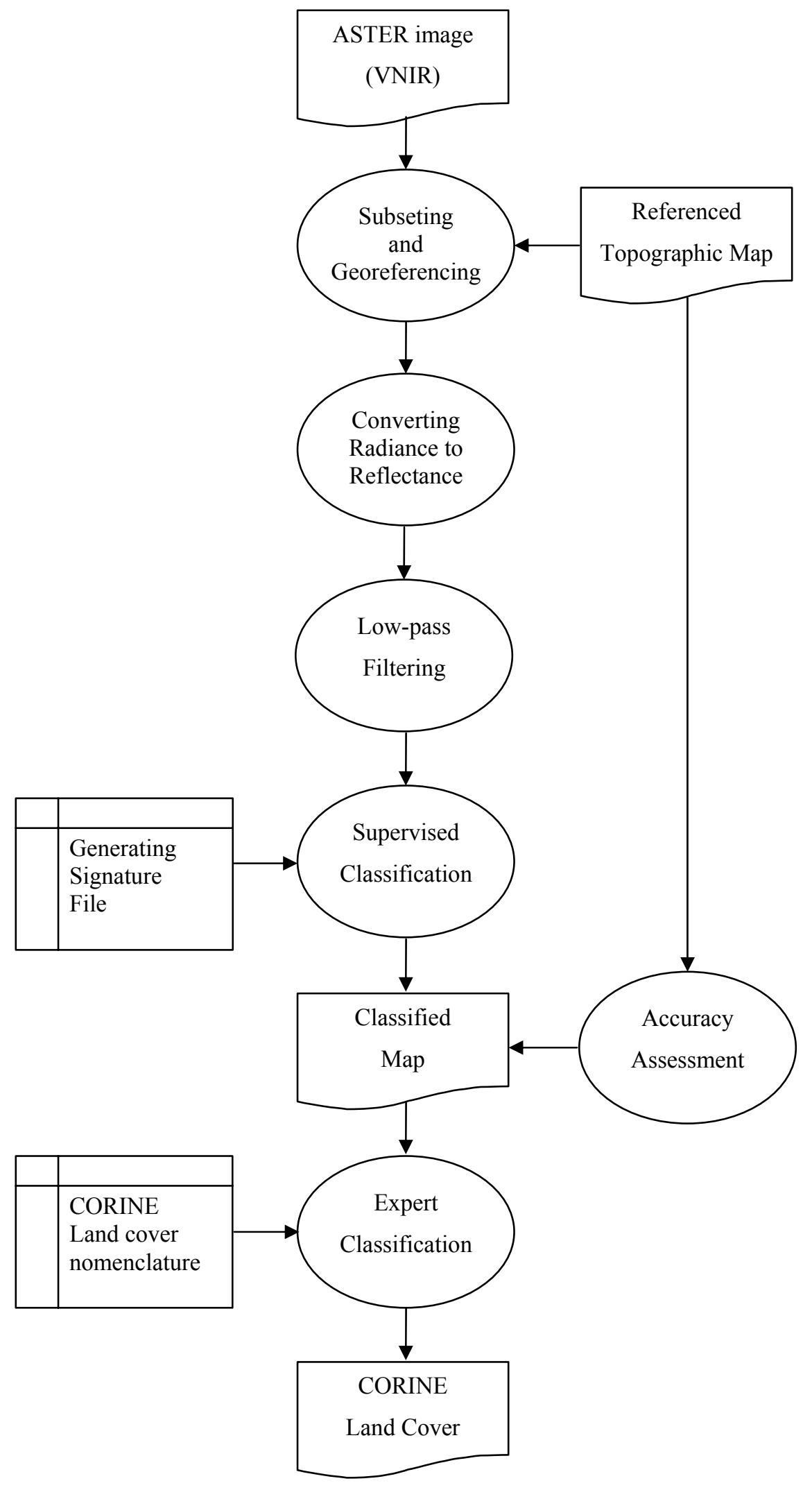

Figure 2. The flowchart indicating image processing stages. 


\subsubsection{Preprocessing}

A Level 1A ASTER image (VNIR) of the study area was acquired on the $16^{\text {th }}$ of August, 2005 with a cloud cover of $0 \%$. In preprocessing stage, first the images were imported into the "image" format in ERDAS Imagine 8.5 software [35] using the built-in ASTER import dialog. Then, the study area was clipped out from the ASTER image by using "Subset" function in ERDAS 8.5, referencing 7.5-minute topographic map (i.e. Gaziantep N38a1). The final image was georeferenced based on a topographic map with 1:25 000 scale and then re-projected into the UTM projection zone 37 and ED 50 datum, using a first-order polynomial nearest-neighbor transformation. Approximately 24 ground control points (GCPs) were used in the rectification process resulting in an overall RMS error of less than 0.5 pixels using a second order polynomial model.

\subsubsection{Converting ASTER Radiance Values to Reflectance}

To eliminate the effects of atmospheric scattering and absorption in the VNIR and to increase the accuracy of surface type classification [24, 26, 29], the ASTER DN values were converted to TOA reflectance by using the procedure reported by [36]. This procedure is divided into two stages; (1) Converting DN values to spectral radiance and (2) Transferring the sensor detected radiance into TOA reflectance. In the first stage, DN values of the sensor measurements are converted into spectral radiance measured $\left(L_{r a d}\right)$ by satellite sensors using the following equation:

$$
\left.L_{\text {rad }}=(D N-1) \times c\right)
$$

where $c$ is the unit conversion coefficient which differs for each ASTER band. In this study, the normal values of $\mathrm{c}$ for each band (Table 1) were obtained from the user guide of ASTER [37]. In the second stage, the sensor detected radiance was transferred into the ground surface reflectance $\left(R_{T O A}\right)$ using Eq. 2:

$$
R_{T O A}=\left(\pi \times L_{r a d} \times d^{2}\right) \div\left(E S U N_{i} \times \cos (z)\right)
$$

where $\pi \approx 3.14159, E S U N_{i}$ is the mean solar exoatmospheric irradiance of each band (Table 1), $z$ is the solar zenith angle, $(z=90$ - solar elevation angle), which is within the ASTER header file, and $d$ is the

Table 1. The values of unit conversion coefficient for the operating bands of ASTER (VNIR).

\begin{tabular}{lcccc}
\hline \multirow{2}{*}{ Band } & \multicolumn{2}{c}{ Coefficient $\left.\left(\mathrm{W} / \mathrm{m}^{2} * \mathrm{sr}^{*} \mathrm{um}\right) / \mathrm{DN}\right)$} & \\
\cline { 2 - 4 }$* \mathrm{ESUN}_{\mathrm{i}}$ & High Gain & Normal & Low Gain 1 & \\
\hline 1 & 0.676 & 1.688 & 2.25 & 1847 \\
2 & 0.708 & 1.415 & 1.89 & 1553 \\
$3 \mathrm{~N}$ & 0.423 & 0.862 & 1.15 & 1118 \\
$3 \mathrm{~B}$ & 0.423 & 0.862 & 1.15 & \\
\hline
\end{tabular}


$* \mathrm{ESUN}_{\mathrm{i}}=$ Calculated by convolving the ASTER spectral response functions [38].

earth-sun distance (in astronomical units), which can be calculated using the following equation in Microsoft EXCEL format [39, 40]:

$$
d=1-0.01672 \times \operatorname{COS}(\text { RADIANS }(0.9856 \times(\text { Julian_Day }-4)))
$$

To evaluate the effects of converting processes, NDVI was calculated for both radiance values and TOA reflectance of ASTER in Band 2 and Band $3 \mathrm{~N}$ by using the following formula:

$\mathrm{NDVI}=($ Band 3N-Band 2$) /($ Band 3N+Band 2$)$

where Band $3 \mathrm{~N}$ is near infrared and Band 2 is visible red reflectance [41].

\subsubsection{Land use/cover classification}

In subset image of the research forest, there was a high frequency of data variability due to heterogonous characteristics of the landscape features. The low-pass filtering technique has been widely used to reduce spatial frequency [42]. Using "Convolution" function in ERDAS 8.5 [43], the performances of three different low-pass filtering standards $(3 \times 3,5 \times 5$, and $7 \times 7)$ were compared [44].

In classification process, Supervised Classification method in ERDAS 8.5 was performed based on a set of user-defined classes, by creating the appropriate spectral signatures from TOA reflectance data. In supervised classification process, "User-Defined Polygon" function reduces the chance of underestimating class variance since it involved a high degree of user control [32]. Over 80 training points were repeatedly selected from the whole study area by drawing a polygon around training sites of interests. Land use/cover classes of these training points were extracted with respect to general knowledge obtained from topographic maps and field visits. In selection process, "Signature Alarm" and "Signature Mean Plot" tools were used to accurately representing the land use/cover classes to be identified. Then, supervised classification was performed using the parallelepiped non-parametric rule provided by ERDAS 8.5. After the classification process, "Recode" function in ERDAS 8.5 was applied to combine the classes into 10 main classes including irrigated crops (1), fallow (2), stubble (3), rangeland (4), sparse forest (5), forest (6), bare land (7), residential (8), wetland (9), and river channel (10).

To evaluate the accuracy of the classified image, "Accuracy Assessment" tool in ERDAS 8.5 was used based on random sampling method in which 256 points were automatically selected from referenced topographic map. The referenced values were recorded on the "Accuracy Assessment Table" based on previously generated topographic map and Color IR air photos of the region, and field reconnaissance taken place in October 2005. In error matrix utility, the reference class values were compared with the classified class values in a $\mathrm{c} x \mathrm{c}$ matrix, where $\mathrm{c}$ is the number of classes (including class 0 ). Then, overall accuracy and kappa values were computed by using user's accuracy (a measure of commission error) and producer's accuracy (a measure of omission error) of each class. 


\subsubsection{Expert Classification}

After supervised classification process, classified image was post-processed by using "Expert Classification System" [43] according to the CORINE land cover nomenclature [34] (Table 2). Expert classification integrates the available knowledge about the area of interest into the classification data space to improve accuracy [41]. In expert classification, first, a referenced raster map was produced by digitizing irrigated and non-irrigated areas, water course, and residential areas

Table 2. The classes used in classification process based on the CORINE land cover nomenclature.

\begin{tabular}{lll}
\hline Level 1 & \multicolumn{1}{c}{ Level 2 } & \multicolumn{1}{c}{ Level 3 } \\
\hline 1. Artificial surfaces & $\begin{array}{l}\text { 1.1. Urban Fabric } \\
\text { 1.2. Industrial, commercial, } \\
\text { and transport units }\end{array}$ & $\begin{array}{l}\text { 1.1.2. Discontinuous urban fabric } \\
\text { 1.2.2. Road and rail networks and } \\
\text { associated land }\end{array}$ \\
2. Agricultural areas & 2.1. Arable land & $\begin{array}{l}\text { 2.1.2.Permanently irrigated land } \\
\text { 3.1.2. Coniferous forest }\end{array}$ \\
3. Forests and semi- & 3.1. Forests & \\
natural areas & 3.2. Shrub and/or herbaceous & 3.2.1. Natural grassland \\
& vegetation association & 3.2.4. Transitional woodland/shrub \\
& 3.3. Open spaces with little or & 3.3.2. Bare rock \\
& no vegetation & \\
4.1. inland wetlands & 4.1. 1. Inland marshes \\
5.1. Inland waters & 5.1.1. Water courses \\
\hline
\end{tabular}

from the referenced topographic map. Table 3 indicates class values in classified, referenced, and CORINE land use/cover maps used in expert classification process. In "Spatial Modeler" tool of ERDAS 8.5 [43], CORINE land use/cover maps were generated by using the conditional statement indicated under Table 3. In these statements, first, the discontinuous urban fabric was delineated when they were classified as fallow and stubble areas in classified land covers, while they were classified as residential in referenced map. Water courses were also delineated when they were classified as fallow and stubble areas in classified land covers, while they were classified as water courses in referenced map. When fallow and stubble were classified as irrigated in reference map, they were assigned as permanently irrigated land, while they were non-irrigated arable land when they were classified as non-irrigated in reference map. 
Table 3. The class values in classified, referenced, and CORINE land use/cover maps used in expert classification process.

\begin{tabular}{|c|c|c|c|c|c|}
\hline \multicolumn{2}{|c|}{$\begin{array}{l}\text { Classified } \\
\text { Land Covers }\end{array}$} & \multicolumn{2}{|c|}{$\begin{array}{c}\text { Reference } \\
\text { Land Covers }\end{array}$} & \multicolumn{2}{|r|}{$\begin{array}{c}\text { CORINE } \\
\text { Land Covers }\end{array}$} \\
\hline Class & Class & Class & Class & Class & CORINE \\
\hline Values & Names & Values & Names & Values & Nomenclature \\
\hline 1 & Irrigated Crops & 1 & Resident & 1 & Permanently irrigated land \\
\hline 2 & Fallow & 2 & Irrigated & 2 & Natural grassland \\
\hline 3 & Stubble & 3 & Water Course & 3 & Transitional woodland/shrub \\
\hline 4 & Rangeland & 4 & Non-irrigated & 4 & Coniferous forest \\
\hline 5 & Sparse forest & & & 5 & Bare rock \\
\hline 6 & Forest & & & 6 & Discontinuous urban fabric \\
\hline 7 & Bare land & & & 7 & Inland marshes \\
\hline 8 & Residential & & & 8 & Water Courses \\
\hline 9 & Wetland & & & 9 & Non-irrigated arable land \\
\hline 10 & Water Courses & & & 10 & $\begin{array}{l}\text { Road and rail networks and } \\
\text { associated land }\end{array}$ \\
\hline
\end{tabular}

Statement Used in ERDAS Spatial Modeler:

CONDITIONAL $\{$ (Reference $==1) 6,($ Reference $==3) 8,($ Classified $==1) 1,($ Classified $==4) 2,($ Classified $==5) 3$,

$($ Classified $==6) 4$, (Classified $==7) 5,($ Classified $==8) 6$, (Classified $==9) 7,($ Classified $==10) 8,($ Classified $==2$ AND

Reference $==1) 6$, (Classified $==2$ AND Reference $==2) 1$, (Classified $==2$ AND Reference $==3) 8,($ Classified $==2$ AND

Reference $==4) 9,($ Classified $=3$ AND Reference $==1) 6,($ Classified $==3$ AND Reference $==2) 1,($ Classified $==3$ AND

Reference $==3) 8$, (Classified $==3$ AND Reference $==4) 9\}$

\section{Results and Discussion}

\subsection{Converting ASTER Radiance Values to Reflectance}

After converting ASTER radiance values to reflectance, their NDVIs were calculated for both radiance values and TOA reflectance to evaluate the effects of converting processes. In previous studies, NDVI was commonly used to evaluate the effects of atmospheric correction process [24, 45, 46,47]. The results shown in Table 4 indicated that the NDVI of the TOA reflectance is greater than that of ASTER radiance values. Thus, quality of the image was improved after eliminating the negative effects of molecular scattering, gaseous observation, and aerosols. Vermote et al. [24] also reported that the NDVI values, on average, increased from -0.26 to 0.10 after atmospheric corrections.

Table 4. Comparison of radiance and TOA reflectance values of NDVI

\begin{tabular}{lcc} 
Statistics & Radiance & Reflectance \\
\hline Min & -0.500 & -0.365 \\
Max & 0.400 & 0.501 \\
Mean & -0.255 & -0.100 \\
Median & 0.342 & -0.019 \\
Mode & -0.402 & -0.257 \\
Std. Dev. & 0.187 & 0.188 \\
\hline
\end{tabular}

\subsection{Land use/cover classification}

The results indicated that applying 7X7 low-pass filter removed the data variation prior to classifications process. Akay et al. [48] also reported that using 7X7 low-pass filter provided better 
results in a study where tree and shrub species were classified. Then, supervised classification was applied to classify the land use/cover types into 10 main classes (Figure 3). The accuracy of the classified image was then assessed by using randomly selected 256 points based on referenced topographic map. The results indicated that classification process provided overall accuracy and kappa values of $83.2 \%$ and 0.79 , respectively (Table 5 ).

Supervised classification provided satisfactory results in terms of distinguishing irrigated crops, forest, stubble, water courses, and rangeland; however, accuracy for fallow, sparse forest, bare land, and residential were relatively low due to large variation of spectral signatures. The highest producers and users accuracy was reached in classification of irrigated crops (96.61\%) and stubble (94.87\%), respectively. The lowest producers and users accuracy was for fallow (57.69\%) and bare land (35.29\%), respectively. It was assumed that low accuracy of the follow is due to close reflection values received from follows, sparse forest, and wetland (Figure 4). The results also indicated that supervised classification overestimated rangeland and bare land, while underestimated irrigated, forest, residential, and water courses. The roads in the study area could not be distinguished during the classification process due to close reflectance values with adjacent raster cells.

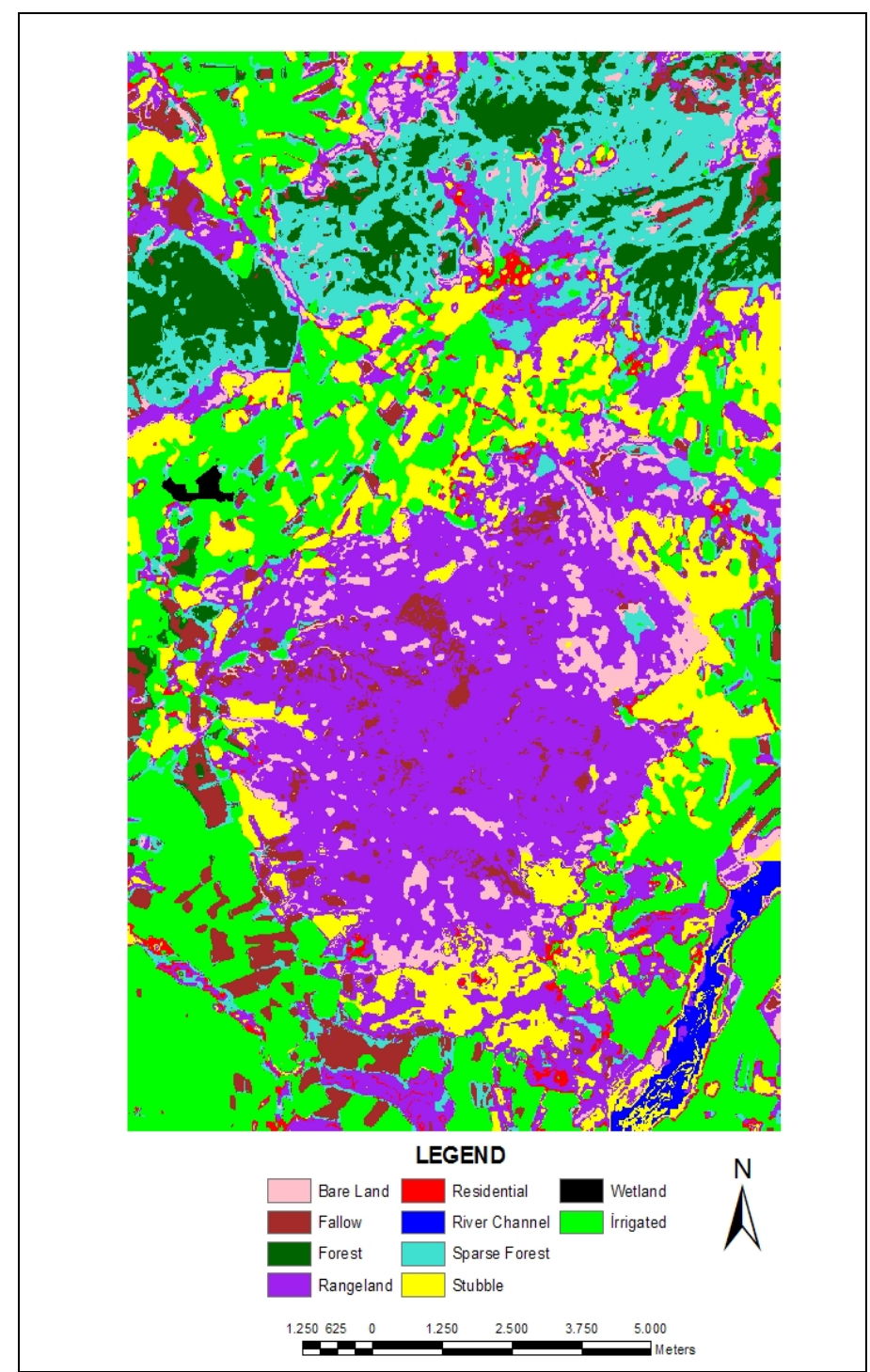

Figure 3. Land use/cover classes after supervised classification of the study area. 
Table 5. The results from the accuracy assessment process.

\begin{tabular}{clccccc}
\hline $\begin{array}{c}\text { Class } \\
\text { Name }\end{array}$ & Class Names & $\begin{array}{c}\text { Reference } \\
\text { Total }\end{array}$ & $\begin{array}{c}\text { Classified } \\
\text { Totals }\end{array}$ & $\begin{array}{c}\text { Number } \\
\text { Correct }\end{array}$ & $\begin{array}{c}\text { Producers } \\
\text { Accuracy }\end{array}$ & $\begin{array}{c}\text { Users } \\
\text { Accuracy }\end{array}$ \\
\hline 1 & Irrigated Crops & 59 & 63 & 57 & $96.61 \%$ & $90.48 \%$ \\
2 & Fallow & 26 & 16 & 15 & $57.69 \%$ & $93.75 \%$ \\
3 & Stubble & 41 & 39 & 37 & $90.24 \%$ & $94.87 \%$ \\
4 & Rangeland & 71 & 70 & 62 & $87.32 \%$ & $88.57 \%$ \\
5 & Sparse forest & 33 & 30 & 20 & $60.61 \%$ & $66.67 \%$ \\
6 & Forest & 12 & 13 & 11 & $91.67 \%$ & $84.62 \%$ \\
7 & Bare land & 7 & 17 & 6 & $85.71 \%$ & $35.29 \%$ \\
8 & Residential & 6 & 7 & 4 & $66.67 \%$ & $57.14 \%$ \\
9 & Wetland & 0 & 0 & 0 & -- & -- \\
10 & Water Courses & 1 & 1 & 1 & $100.0 \%$ & $100.0 \%$ \\
\hline Totals & & 256 & 256 & 213 & & \\
\hline$*$ Overall Classification Accuracy & $=83.20 \%$ & & & & \\
$*$ Overall Kappa Statistics $=0.79$ & & & & &
\end{tabular}

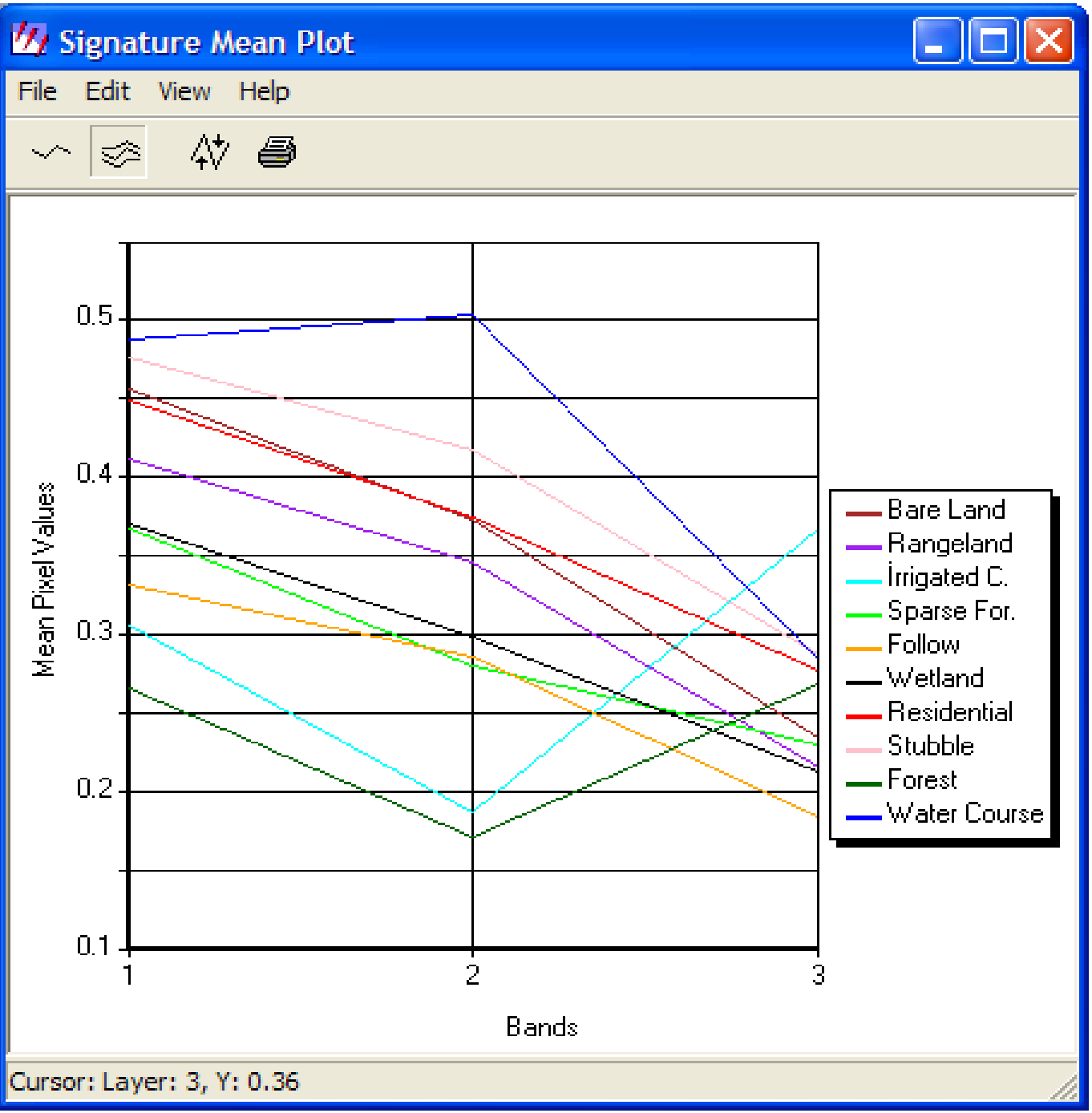

Figure 4. Mean pixel value of the ten classes generated by supervised classification. 


\subsection{Expert Classification}

In the Mediterranean region of Turkey, cereals grow in both irrigated and non-irrigated (rainfed) conditions in winter seasons. It is not easy to determine whether they grow in irrigated or rainfed conditions. Besides, some of the irrigated and non-irrigated lands were not cultivated, which leads to problems in distinguishing permanently irrigated lands from non-irrigated arable land. Thus, expert classification system was applied to improve the accuracy of the classified image and arrange the classes according to the CORINE nomenclature [49]. The results from the expert classification were shown in Table 6, indicating the total area and percentages of land use/cover classes based on CORINE Nomenclature. Figure 5 indicates the land use/cover map of the study area according to CORINE Land Cover Project.

\section{Conclusions}

ASTER sensor imagery, converted into TOA reflectance, was used to generate land use/cover maps according to the CORINE Land Cover Project. Supervised classification process using the TOA reflectance data provided accurate and low-cost land use/cover maps for heterogeneous Mediterranean landscapes. Knowledge-based expert classification system was further applied to improve the accuracy of the classified image and arranged the classes according to the CORINE nomenclature. The method used in this study is expected to contribute to the generation of land use/covers maps for the Mediterranean regions of Europe as a part of CORINE land cover dataset.

Table 6. The total area and percentages of land use/cover classes based on CORINE nomenclature.

\begin{tabular}{clcc}
\hline $\begin{array}{c}\text { Class } \\
\text { Values }\end{array}$ & \multicolumn{1}{c}{$\begin{array}{c}\text { CORINE } \\
\text { Nomenclature }\end{array}$} & Percentage & Area (ha) \\
\hline 1 & Permanently irrigated land & 0.33 & 7206.17 \\
2 & Natural grassland & 0.28 & 6107.20 \\
3 & Transitional woodland/shrub & 0.11 & 2504.16 \\
4 & Coniferous forest & 0.06 & 1385.10 \\
5 & Bare rock & 0.05 & 1199.20 \\
6 & Discontinuous urban fabric & 0.04 & 778.21 \\
7 & Inland marshes & 0.00 & 36.45 \\
8 & Water Courses & 0.02 & 473.85 \\
9 & Non-irrigated arable land & 0.10 & 2121.39 \\
10 & $*$ Road and rail networks and associated land & -- & -- \\
\hline
\end{tabular}

* Class 10 could not be distinguished from the adjacent classes during the classification process. 


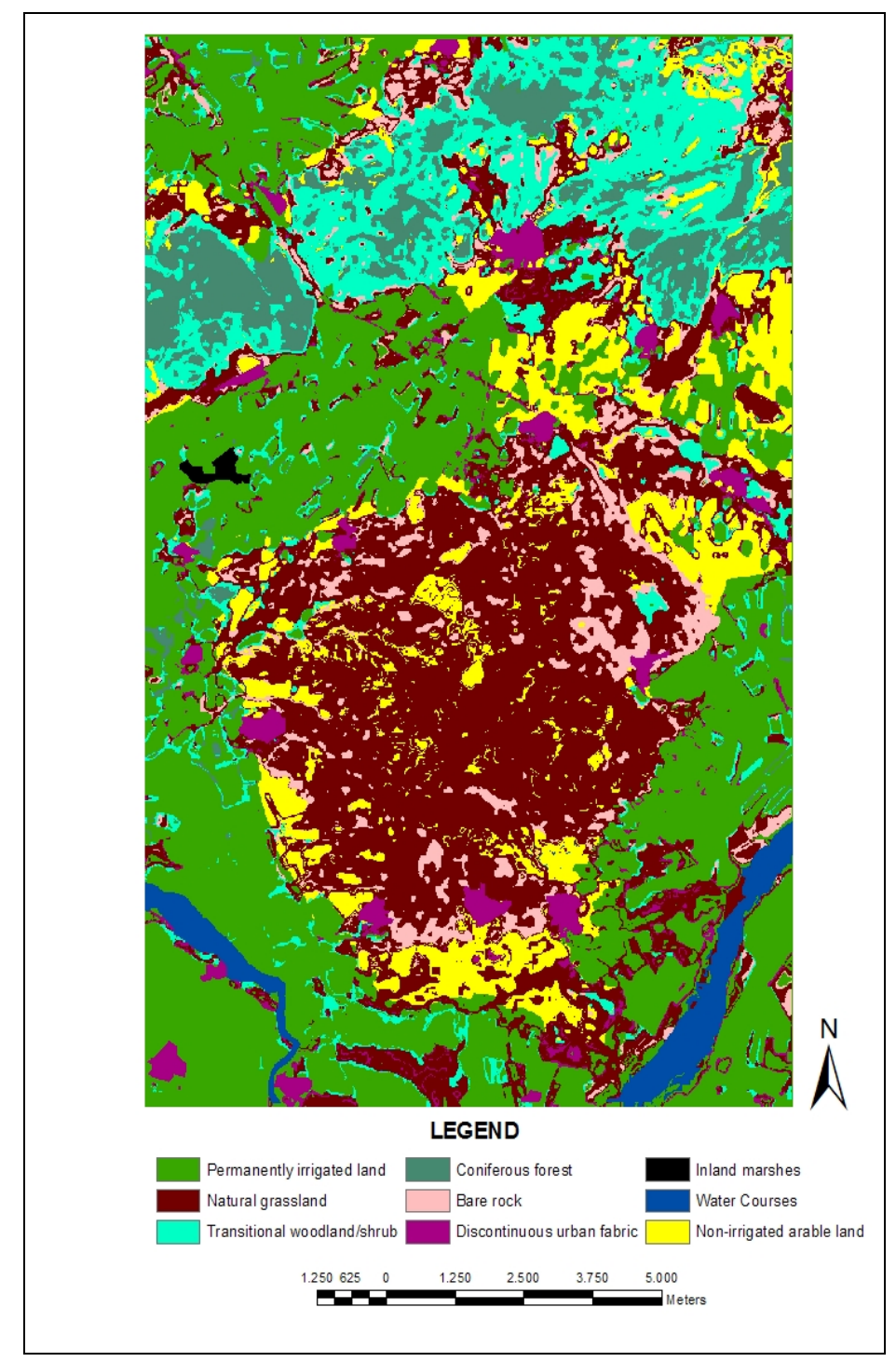

Figure 5. The land use/cover map of the study area according to CORINE Land Cover Project.

\section{Acknowledgement}

The authors are grateful to Michael J. Falkowski, Paul E. Gessler, and Alistair M.S. Smith in University of Idaho, Geospatial Laboratory for Environmental Dynamics (GLED) for their assistance in analysis of top-of-atmospheric correction. This work was financially supported by the Scientific and Technological Research of Turkey (TUBITAK) as part of research grant no. TOVAG $106 \mathrm{O} 126$.

\section{References}

1. Alrababah, M.A.; Alhamad, M.N. Land use/cover classification of arid and semi-arid Mediterranean landscapes using Landsat ETM.International Journal of Remote Sensing 2006, 27, 2703-2718.

2. Vogelmann, J.E.; Helderb, D.; Morfitta, R.; Choatea, M. J.; Merchantc, J.W.;Bulley, H. Effects of Landsat 5 Thematic Mapper and Landsat 7 Enhanced Thematic Mapper Plus radiometric and 
geometric calibrations and corrections on landscape characterization. Remote Sensing of Environment 2001, 78, 55-70.

3. Berberoglu, S.; Lloyd, C.D.; Atkinson, P.M.; Curran, P.J. The integration of spectral and textural information using neural networks for land cover mapping in the Mediterranean. Computers and Geosciences 2000, 26, 385-396.

4. Calvao, T.; Palmeirim, J.M. Mapping Mediterranean scrub with satellite imagery: Biomass estimation and spectral behaviour. International Journal of Remote Sensing 2004, 25, 3113-3126.

5. Koutsias, N.; Karteris, M. Classification analyses of vegetation for delineating forest fire fuel complexes in a Mediterranean test site using satellite remote sensing and GIS. International Journal of Remote Sensing 2003, 24, 3093-3104.

6. Lobo, A.; Legendre, P.; Rebollar, J.L.G.; Carreras, J.; Ninot, J.M. Land cover classification at a regional scale in Iberia: Separability in a multi-temporal and multi-spectral data set of satellite images. International Journal of Remote Sensing 2004, 25(1), 205-213.

7. Hirataa, M.; Kogab, N.; Shinjoc, H.; Fujitad, H.; Gintzburger, G.; Miyazaki, A. Vegetation classification by satellite image processing in a dry area of northeastern Syria. International Journal of Remote Sensing 2001, 22, 507-516.

8. Vieira, I.G.C.; De Almeida, A.S.; Davidson, E.A.; Stone, T.A.; De Ccarvalho, C.J.R.; Guerrero, J.B. Classifying successional forests using Landsat spectral properties and ecological characteristics in eastern Amazonia. Remote Sensing of Environment 2003, 87, 470-481.

9. Zheng, D.; Rademacher, J.; Chen, J.; Crow, T.; Bresee, M.; Moine, J.L.; Ryu, S.-R.; Estimating aboveground biomass using Landsat $7 \mathrm{ETM}+$ data across a managed landscape in northern Wisconsin, USA. Remote Sensing of Environment 2004, 93, 402-411.

10. Anderson, A. B.; Wang, G.; Gertner, G. Local variability based sampling for mapping a soil erosion cover factor by co-simulation with Landsat TM images. International Journal of Remote Sensing 2006, 27, 2423-2447.

11. Shi, P.J.; Yuan, Y.; Zheng, J.; Wang J.A.; Ge, Y.; Qiu, G.Y. The effect of land use/cover change on surface runoff in Shenzhen region, China. Catena 2007, 69, 31-35.

12. De Jong, B.H.J. Land-Use Change and Carbon Flux Between 1970s and 1990s in Central Highlands of Chiapas, Mexico. Environmental Management 1999, 23, 373-385.

13. Evrendilek, F. Integrating Map Algebra and Statistical Modeling for Spatio-Temporal Analysis of Monthly Mean Daily Incident Photosynthetically Active Radiation (PAR) over a Complex Terrain. Sensors 2007, 7, 3242-3257.

14. Evrendilek, F.; Berberoglu, S.; Gulbeyaz, O.; Ertekin, C. Modeling Potential Distribution and Carbon Dynamics of Natural Terrestrial Ecosystems: A Case Study of Turkey. Sensors 2007, 7, 2273-2296.

15. Cohen, W.B.; Goward, S.N. Landsat's role in ecological applications of remote sensing. Bioscience 2004, 54, 535-545.

16. Musaoglu, N.; Coskun, M.; Kocabas, V. Land use change analysis of Beykoz- Istanbul by means of satellite images and GIS. Water Science and Technology 2005, 51, 245-251.

17. Benedetti, R.; Rossini, P.; Taddei, R. Vegetation classification in the middle Mediterranean area by satellite data. International Journal of Remote Sensing 1994, 15, 583-596. 
18. Abrams, M. The Advanced Spaceborne Thermal Emission and Reflection Radiometer (ASTER): data products for the high spatial resolution imager on NASA's Terra platform. International Journal of Remote Sensing 2003, 21(5), 847-859.

19. Rowan, L.C.; Mars, J.C. Lithologic mapping in the Mountain Pass, California area using advanced spaceborne thermal emission and reflection radiometer (ASTER) data. Remote Sensing of Environment 2003, 84, 350-366.

21. Zhu, G.; Blumberg, D.G.; Classification using ASTER data and SVM algorithms; the case study of Beer Sheva, Israel. Remote Sensing of Environment 2001, 80, 233-240.

22. Davis, F. W.; Simonett, D. S. GIS and remote sensing. In Geographical information systems: principles and applications; Maguire, D.J., Goodchild, M.F., Rhind, D.W., Eds.; Longman Scientific and Technical: London, GB, 1991; pp. 191-213.

23. Jensen, J.R. Introductory Digital Image Processing: A Remote Sensing Perspective $3^{\text {rd }}$ Ed.; Prentice-Hall: Upper Saddle River, NJ, 2005.

24. Vermote E. F.; El Saleous, N.Z.; Justice, C. O. Atmospheric correction of MODIS data in the visible to middle infrared: first results. Remote Sensing of Environment 2002, 83, 97-111.

25. Song, C.; Woodcock, C.E.; Seto, K.C.; Lenney, M.P.; Macomber, S.A. Classification and Change Detection Using Landsat TM Data: When and How to Correct Atmospheric Effects? Remote Sensing of Environment 2001, 75, 230-244.

26. Kaufman, Y.J. The atmospheric effect on the separability of field classes measured from satellites. Remote Sensing of Environment 1985, 18, 21-34.

27. Richter, R. A spatially adaptive fast atmospheric correction algorithm. International Journal of Remote Sensing 1996, 17, 1201-1214.

28. Teillet, P. M. An algorithm for the radiometric and atmospheric correction of AVHRR data in the solar reflective. Remote Sensing Environment 1991, 41, 185-195.

29. Falkowski, M.J.; Gessler, P.E.; Morgan, P.; Hudak, A.; Smith, T. Characterizing and mapping forest fire fuels using ASTER imagery and gradient modeling. Forest Ecology and Management 2005, 217, 129-146.

30. Berberoglu, S.; Evrendilek, F.; Ozkan, C.; Donmez, C. Modeling Forest Productivity Using Envisat MERIS Data. Sensors 2007, 7, 2115-2127.

31. Xiaoling, C.; Xiaobin, C.; Hui, L. Expert classification method based on patch-based neighborhood searching algorithm. Geo-Spatial Information Science 2006, 10(1), 37-43.

33. Moller-Jensen, L. Classification of Urban land cover based on expert systems, object models and texture. Computers, Environment and Urban Systems 1997, 21, 291-302.

34. EEA, CORINE Land Cover. European Environment Agency. Acquired from http://reports.eea.europa.eu/CORO-landcover/en. Accessed in January 2008.

35. ERDAS/Leica Geosystem. ERDAS Imagine 8.5. Tour Guide. 2001, Atlanta: ERDAS Inc. Geosystem.

36. Smith, A.M.S. How to Convert ASTER Radiance Values to Reflectance. An Online Guide. Acquired from www.cnrhome.uidaho.edu/default.aspx?pid=85984, College of Natural Resources , University Idaho.

37. Abrams, M.; Hook, S. ASTER User Handbook, 1998, Version 1, NASA/Jet Propulsion Laboratory, Pasadena. 
38. Thome, K.; Biggar S.; Slater P. Effects of assumed solar spectral irradiance on intercomparisons of earth-observing sensors. In Sensors, Systems, and Next-Generation Satellites. Proceedings of SPIE, December 2001; Fujisada, H., Lurie, J., Weber, K., Eds.; Vol. 4540, p. 260-269.

39. Archard, F.; D'Souze, G. Collection and pre-processing of NOAA-AVHRR $1 \mathrm{~km}$ resolution data for tropical forest resource assessment. Report EUR 16055 for European Commission, Luxembourg, 1994.

40. Eva, H.; Lambin, E.F. Burnt area mapping in Central Africa using ATSR data. International Journal of Remote Sensing 1998, 19, 3473-3497.

41. Jensen, J. R. Remote sensing of the environment: An earth resource perspective. Prentice-Hall: Upper Saddle River, NJ, 2000.

42. Lillesand, T.M.; Kiefer, R.W. Remote Sensing and Image Interpretation. John Wiley \& Sons: New York, NY, 1994; pp. 750.

43. ESRI. ERDAS Imagine 8.5. Field Guide; ESRI Inc.: Atlanta, 2001.

44. Akay, A.E.; Tutus, A. Using Image Analysis in Estimating Blue Stain Defects on Fire-Killed Brutian Pine (Pinus brutia). Wood Research Journal 2006, 51(1), 41-48.

45. Stefanov, W.L.; Netzband, M. Assessment of ASTER land cover and MODIS NDVI data at multiple scales for ecological characterization of an arid urban center. Remote Sensing of Environment 2005, 99, 31-43.

46. Chen, X.; Vierling, L.; Deering D. A simple and effective radiometric correction method to improve landscape change detection across sensors and across time. Remote Sensing of Environment 2005, 98, 63-79.

47. Richter, R.; Schlapfer, D.; Muller, A. An automatic atmospheric correction algorithm for visible/NIR imagery. International Journal of Remote Sensing 2006, 26, 2077-2085.

48. Akay, A.E.; Karas, I.R.; Gundogan, R. Classification of Tree and Shrub Species in KSU Research and Application Forest In Kahramanmaras, Turkey. In Proc. 10th Intl. Symposium on Physical Measurements and Spectral Signatures in Remote Sensing; Schaepman, M., Liang, S., Groot, N., Kneubühler, M., Eds. Intl. Archives of the Photogrammetry, Remote Sensing and Spatial Information Sciences, Vol. XXXVI, WG VII/I, pp. 334-337. ISPRS, Davos (CH). ISSN 16821777, 2007.

49. Tapiador, F. J.; Casanova, J.L. Land use mapping methodology using remote sensing for the regional planning directives in Segovia, Spain. Landscape and Urban Planning 2003, 62, 103115.

(C) 2008 by MDPI (http://www.mdpi.org). Reproduction is permitted for noncommercial purposes. 